\title{
An important aspect of structural design of super-tall buildings and structures: Across-wind loads and effects
}

\begin{abstract}
Across-wind loads and effects have become increasingly important factors in the structural design of super-tall buildings and structures with increasing height. Although researchers have investigated the problem for over 30 years, the research achievements of across-wind loads and effects and the computation methods of equivalent static wind loads are still not satisfactory. Professor GU Ming and his group from the State Key Laboratory of Disaster Reduction in Civil Engineering set out to tackle this problem. After more than 10 years of innovative research, they have obtained many results for across-wind loads on super-tall buildings and structures with various cross-sections and developed new methods for determining across-wind aerodynamic damping and across-wind equivalent static wind loads. These achievements have been adopted in national and local load codes and have been applied to the structural design of a large number of actual super-tall buildings and structures. Their work, entitled "Across-wind loads and effects of super-tall buildings and structures", was published in Science China Technological Sciences.
\end{abstract}

Professor GU Ming and his group have performed a series of wind tunnel tests on models of typical tall buildings and structures for across-wind forces employing a wind pressure scanning technique and high-frequency force balance technique. There were a total of 121 general building models and dozens of real tall structure models. Twenty-five building models for wind pressure tests and 96 building models for direct measurements of wind forces were sampled employing the high-frequency force balance technique. The models had different cross-section shapes, namely a square, rectangular, triangle, Y shape, polygon, L shape, corner-modified square, ladder shape, twin-tower shape, and a shape with a continuously contracting cross section.

Formulas for across-wind aerodynamic forces were derived for practical use from many experimental results obtained in wind tunnel tests. As an example, a unified formula for the non-dimensional power spectra density of the across-wind force acting on rectangular buildings and square buildings with corner modifications was derived. The formula has better features than previous formulas.

Aeroelastic models were used to investigate the aerodynamic damping characteristics of buildings. A base for supporting the aeroelastic models of tall buildings was specially designed for the tests. The frequency, mass distribution, and damping of the aeroelastic models could be easily adjusted for parametric study. Three series of buildings, namely rectangular buildings, corner-modified square buildings, and buildings with continuously contracting cross sections, were modeled and tested under four categories of terrain conditions in the TJ-1 Boundary Layer Wind Tunnel at Tongji University. The effects of the cross-section shape and dynamic parameter of buildings as well as the terrain condition on the aerodynamic damping were thoroughly investigated. The time-averaging method of the random-decrease technique and the stochastic sub-space identification method were adopted in the current study to identify the aerodynamic damping ratio. On the basis of testing results and analyses, a formula for the aerodynamic damping ratio of a square building was derived for practical purposes.

A new method of determining the across-wind equivalent static wind load was also developed. The across-wind equivalent static wind load was firstly divided into mean, resonant and background components for separate computation, and these components were combined as the total equivalent static wind load. The resonant component is equal to the inertial force due to vibration of the structure and the background component is essentially the base-moment-based equivalent static wind load.

Since there is no corresponding guidance in the present Chinese code, the across-wind loads and responses have not been considered by structural engineers for many super-tall buildings and structures. As an important application, the above new formulas and methods have been adopted in the national code of China and a local load code and have also been directly applied to the structural design of many super-tall buildings and structures.

The recent trend of constructing higher buildings and structures implies that wind engineering researchers will face new challenges, even problems they are currently unaware of. Therefore, there needs to be more effort to resolve engineering design problems and to further the development of wind engineering.

See the article: Gu M, Quan Y. Across-wind loads and effects of super-tall buildings and structures. Sci China Tech Sci, 2011, 54: 2531-2541, doi: $10.1007 / \mathrm{s} 11431-011-4543-5$

Open Access This article is distributed under the terms of the Creative Commons Attribution License which permits any use, distribution, and reproduction in any medium, provided the original author(s) and source are credited. 